\title{
Carpal Tunnel Release Using Nasal Instruments
}

\section{Ashraf Hussein $^{(1)}$, Waleed Al Dabaany ${ }^{(2)}$, Sherif Maher $^{(3)}$, Peter Awny Mikhail Saif ${ }^{(4)}$}

${ }^{(1)}$ Professor of General \& Plastic Surgery, Faculty of Medicine, Fayoum University

${ }^{(2)}$ Assisstant Professor of General \& Plastic Surgery, Faculty of Medicine, Fayoum

University

${ }^{(3)}$ Lecturer of General Surgery \& Plastic Surgery, Faculty of Medicine, Fayoum

University

${ }^{(4)}$ M.B.B.Ch. Faculty of Medicine, Ain Shams University

Corresponding autor: +0201229762897

E-mail: neurosurgeon.pa@gmail.com

\begin{abstract}
Background: Carpal tunnel syndrome (CTS) results from compression of the median nerve at the wrist. Intermittent compression of the nerve results in numbness and parasthesias. Surgical treatment is generally recommended in cases that fail to respond to conservative measures. A variety of surgical techniques have been described for the treatment of carpal tunnel syndrome. The open incision technique has some disadvantages related to the procedure. So, Recent studies aim to decrease these complications by mini open incisions. Performing a mini incision technique by using nasal instruments has tremendous advantages and very satisfying results.
\end{abstract}

Objective: To assess the feasibility of the mini incision technique using nasal instruments to release carpal tunnel.

Methods: In this study, we performed a mini incision technique by using nasal instruments to 20 hands of patients suffering of carpal tunnel syndrome. We included all patients with carpel tunnel syndrome with positive conduction studies. We exclude the patients with cervical radiculopathy, recurrent CTS, and the Patients having CTS, due to traumatic fracture. We used a symptoms score called 6 item score. That depends on pain severity tingling and numbness severity at day time and at night, preoperative and postoperative, awakening at night due to pain or tingling preoperative and postoperative .We also compared between tinnel's test, phalen's test, motor velocity and latency and sensory latency preoperative and postoperative, no major complications occurred (recurrence, injuries) at the time of the study, minor complications however, were quite common and included delayed healing, postoperative pain that required analgesics.

Results: In cases of a carpel tunnel syndrome, modified open technique by 
a mini incision technique by using nasal instruments less time was consumed than other techniques, reasonable exposure rates and more easy to cut the transverse carpal ligament safely unless very thick tough or calcified, greatly improves all symptoms like pain severity tingling and numbness severity at day time and at night and awakening times at night due to pain or tingling, and improves the nerve function and conductivity studies as tinnel test, phalen test, motor velocity and latency and sensory latency. No injury to any of the structures had occurred and no patient came back for revision, and all patients had symptoms relieved.

Conclusion: In cases of a carpel tunnel syndrome, modified open technique by a mini incision technique by using nasal instruments having satisfying results, greatly improves all symptoms like pain severity tingling and numbness severity at day time and at night. No major complications like recurrence nor injuries occured.

Keywords: Carpal Tunnel Release; Carpal Tunnel Syndrome; Nasal Instruments; distal volar forearm fascia

\section{INTRODUCTION}

Carpal tunnel syndrome (CTS) is the most common and widely known of the entrapment neuropathies in which the body's peripheral nerves are compressed ${ }^{[1,2]}$ Common symptoms of CTS involve the hand (numbness, pain and, eventually, hand weakness) and result from compression of the median nerve within the carpal tunnel. In the great majority of cases, CTS is called idiopathic. Secondary CTS may be related to abnormalities of the container or content. Furthermore, dynamic CTS is frequently found under pathological conditions relating to manual work ${ }^{[3]}$. The median nerve controls sensations to the palm side of the thumb and fingers (except for the little finger), as well as impulses to some muscles in the hand that moves the thumb and fingers.

syndrome

Diagnosing carpal tunnel

The median nerve is accessible in front of the wrist flexion crease and behind the long palmar tendon or in the middle of the wrist.

-Tinel sign: the test is positive if the patient perceives paresthesia during manual percussion on the palmar face of the wrist at the level of the median nerve.

-Phalen sign: the test is positive if, during maximum active flexion of the wrist for $1 \mathrm{~min}$ (elbow extended), paresthesia appears in the area of the median nerve. The time taken for the symptoms to appear (in seconds) is noted.

-Paley and McMurphy test: ${ }^{[3]}$ the sign is positive if manual pressure close to the median nerve (between 1 and $2 \mathrm{~cm}$ proximally to the wrist flexion crease) triggers pain or paresthesia.

- Compression test with wrist flexed: ${ }^{[3]}$ pressure is applied using two fingers on the median region of the carpal tunnel, with the wrist flexed at $60 \circ$, elbow extended and forearm supinated. The test is positive if 
paresthesia appears in the area of the median nerve.

syndrome

Treating carpal tunnel

Conservative treatment

In relation to corticoid injection, immobilization by means of orthotic braces and oral corticoid therapy, the level of evidence is sufficient to confirm their effectiveness. There is controversy in relation to other treatments (ultrasound, laser, diuretics, vitamin B6 therapy and weight loss). ${ }^{[5}$, 6]

\section{Surgical treatment}

The principle of surgical treatment is to achieve a reduction in intratunnel pressure through increasing the volume of the carpal tunnel, by sectioning the flexor retinaculum. The procedure is done under locoregional or local anesthesia, ideally as an outpatient procedure, and frequently using a tourniquet. The procedure is generally unilateral. Four techniques are currently used

Open procedures.

Techniques known as "mini-open."

Endoscopic techniques.

Ultrasound guided minimally invasive technique.

\section{The open technique}

The oldest form of treatment. An incision of $3-4 \mathrm{~cm}$ is made, extending from the wrist flexion crease along the prolongation of the radial edge of the fourth finger to Kaplan's cardinal line (a line drawn from the junction of metacarpaophalangeal (MCP) joint line of the thumb at the first interdigital fold to a point $2 \mathrm{~cm}$ distal to pisiform) [7] The fat pad of the hypothenar region [8] is interposed at the end of the surgery between the skin and the flexor retinaculum. Following this, the middle palmar aponeurosis is incised radially. Subcutaneous dissection preserving the sensory branches that are susceptible to creating postoperative pain was not shown to be superior to direct incision of the flexor retinaculum using a scalpel [9] Hemostasis through bipolar coagulation is a requirement. The flexor retinaculum is exposed using separators. The dissection forceps identify the hamate hook. The middle part of the flexor retinaculum is then incised on the ulnar side of the axis, in the fourth finger, and an ulnar margin is left in order to limit the subluxation of the flexors. Sectioning of the flexor retinaculum continues cautiously in the distal direction until reaching the superficial palmar arch and the median-ulnar anastomosis. Proximally, the flexor retinaculum is separated at deep levels from the synovium of the flexors, using dissection scissors.

Techniques described as "miniopen"

- Mini-open technique with incision close to the flexor retinaculum: ${ }^{[10]}$ a cutaneous incision of $1-1.5 \mathrm{~cm}$ is made in the distal part of the flexor retinaculum, starting from Kaplan's cardinal line, on the axis of the radial edge of the fourth finger. The flexor retinaculum is then incised distally, in the distal-to-proximal direction using scissors by means of spacers, as far as the proximal part. ${ }^{[10]}$ 
- Mini-open technique with incision at the wrist flexion crease: the flexor retinaculum is not viewed and there is no interposition, and then closure with simple sutures. With a potential risk of iatrogenic injury and/or incomplete sectioning of the flexor retinaculum. Paine and Polyzoidis [3] used a "retinaculotome" to protect the content of the carpal tunnel. Durandeau ${ }^{[11]}$ used a probe channel for this function and this is the preferred technique.

- Mini-open technique with double edges: with a distal edge to help protect the neurovascular elements. The flexor retinaculum is again not view, except when sectioned. The techniques of Chaise et al. ${ }^{[12]}$ and Bowers as mentioned by Beckenbaugh ${ }^{[13]}$ can be cited, with the addition of a proximal incision, $1 \mathrm{~cm}$ distally from the hamate hook, with a protection retractor. Lee and Strickland ${ }^{[3]}$ used a special scalpel with trans-illumination. carpal tunnel

Endoscopic surgery on the

Endoscopic surgery on the carpal tunnel was started in Japan by Okutsu, and then in the United States by Chow. Chow's technique involves two surgical approaches, and complications inherent to the distal incision have limited its use, thus favoring the technique of Agee et al., ${ }^{[3]}$ which uses a single proximal incision. Furthermore, because the wrist is placed in hyperextension in Chow's technique, the intratunnel pressure is considerably increased, which may cause acute compression of the median nerve before the operation. A longer learning curve is required Agee's technique: Agee's technique is the one that is used most, performed under regional anesthesia after performing local antisepsis. The approach route is of length $1 \mathrm{~cm}$, at a distance of $0.5-1.0$ $\mathrm{cm}$ proximally to the wrist flexion crease, over the ulnar edge of the palmaris longus muscle. The subcutaneous dissection makes it possible to expose the fascia of the forearm. It needs to be checked whether the incision is in the extrabursal space. A disposable blade is used, lubricated on its deep surface to facilitate its introduction, which is done on the axis of the fourth finger. Progression of the incision is slow, under endoscopic control, by means of sliding the disposable blade against the deep surface of the flexor retinaculum. If viewing is imperfect or introduction of the instrument is difficult, the operation should be converted into an open procedure. The patient should be informed about the possibility of conversion before the procedure is started. The incision should progress until the distal fat pad is seen. Sectioning of the flexor retinaculum is started distally.

Using nasal instruments as Killian nasal turbinate speculum, and Ballenger Swivel nasal septal knife in carpal tunnel release by the taking advantage of the two blades of the Killian nasal turbinate speculum as one blade is put under the transverse carpal ligament, and the other blade above it to protect the nerve and ensure complete sectionning by the knife , as visualization of distal volar forearm fascia is easy now by means of the speculum. 


\section{AIM OF THE WORK}

To assess the feasibility of the mini incision technique using nasal instruments to release carpal tunnel.

\section{PATIENTS AND METHODS}

\section{Study design}

This prospective study includes 20 hands of patients undergoing carpal tunnel release for treatment of carpal tunnel syndrome in Fayoum University Hospitals and Arab Contractors Medical Center with approved ethical committee consents. All patients received information about surgical technique and risks of the procedure and written consent was taken from all patients.

The thirty patients were recruited in the study according to the following inclusion criteria: all patients suffering from carpal tunnel syndrome with positive nerve conduction studies.

Exclusion Criteria of the study were: patients with cervical radiculopathy, patients having recurrent CTS, Patients having CTS due to traumatic fracture.

\section{Procedure}

\section{Preoperative patients were evaluated} by:

○ Full History taking, History includes severity of symptoms.

○ Examination, Phalen's and Tinel's tests.
○ Investigations, nerve conduction studies.

○ All patients received information about surgical technique and risks of the operation.

O Giving instructions to patients about the importance of Volar slapping for two weeks, patients were encouraged to move their fingers to help prevent stiffness and instructed to keep the affected hand elevated while sleeping at night to help decrease swelling after procedure.

\section{Carpal tunnel release using nasal instruments:}

All the patients underwent carpal tunnel release using nasal instruments in operation room under optimum temperature $24^{\circ} \mathrm{C}$ under general anesthesia.

\section{Operative details}

○ Patient preparation, general anaesthesia, tourniquet appliance, disinfection and drapping.

○ Under complete aseptic conditions in operating room small longitudinal incision about 2 centimeters was done in midpalmar region along the prolongation of the radial edge of the fourth finger.

- Conventional release of distal part of transverse carpal ligament was done.

- A nasal speculum inserted one blade below the transverse carpal ligament and the other blade above the ligament to release the proximal part of it. 
O By a nasal septal knife dissection of the transverse carpal ligament and the distal volar forearm fascia was done to ensure complete release.

$\bigcirc$ Good haemostasis and wound closure.

\section{Postoperative patients care:}

○ Postoperative volar slapping was applied to all patients immediately after the procedure for 2 weeks.

O All patients were encouraged move their fingers to help prevent stiffness and instructed to keep the affected hand elevated while sleeping at night to help decrease swelling.

O All patients were discharged on the same day on anti-inflammatory drugs, antibiotics, and pain killers.

○ Documentation of early postoperative major complications e,g. bleeding or severe pain.

○ Stitches were removed 15 days post-operatively.
O All patients had nerve conduction studies 3 months post-operatively, Six item score was reevaluated 3 month postoperatively, Tinnel's and Phalen's tests reexamined and nerve conduction studies were and compared with the preoperative results.

\section{Statistical Analysis}

The collected data was organized, tabulated and statistically analyzed using SPSS software statistical computer package version 18 (SPSS Inc, USA). For quantitative data, the mean, median, standard deviation (SD) and range were calculated. Wilcoxon signd-rank test was used in comparing between the two readings of study variables, before and after intervention. For qualitative data the number and percent distribution was calculated; McNemar test was used as test of significance, significance was adopted at $\leq 0.05$. 


\begin{tabular}{|l|c|c|}
\hline \multicolumn{1}{|c|}{ Variable } & Mean \pm SD & Median (Range) \\
\hline Age (years) & $41.4 \pm 7.7$ & $42(26-55)$ \\
\hline \hline \multicolumn{1}{|c|}{ Variable } & N & $\%$ \\
\hline Male & 5 & 25.0 \\
\hline Female & 15 & 75.0 \\
\hline
\end{tabular}

\section{RESULTS}

A total of 20 hands belonging to 20 patients were included in this study. Patients included 15 women of a percentage of $75 \%$ and 5 men of a percentage of $5 \%$ aged from 26 to55 years, with mean (41.4 \pm 7.7$)$. Table 1

Sacia-demagraphic characteristics of study participants $(\mathcal{N}=20)$

Table 1

Of 20 hands of patients suffering from carpal tunnel syndrome, two patients had diabetes mellitus and another two were hypertensives, operated upon by using nasal instruments mini incision of $2 \mathrm{~cm} .10$ hands (50\%) of patients were good exposure, 9 hands (45\%) of patients had fair exposure and 1 hand $(5 \%)$ of patients had bad exposure. 
Two patients $(10 \%)$ with very thick transverse carpal ligaments we needed to extend the wound to $2.5 \mathrm{~cm}$.

\begin{tabular}{||l|c||c||}
\hline \multicolumn{1}{|c|}{ Complications: } & N & \% \\
\hline \hline \multicolumn{1}{|c||}{ Comle } & $\mathbf{3}$ & $\mathbf{1 5 . 0}$ \\
\hline Yes & 1 & $\mathbf{5 . 0}$ \\
Delayed healing beyond 2 weeks & 1 & $\mathbf{5 . 0}$ \\
Delayed healing up to 2 months & 1 & $\mathbf{5 . 0}$ \\
Delayed epidermal healing & & \\
\hline No & $\mathbf{1 7}$ & $\mathbf{8 5 . 0}$ \\
\hline
\end{tabular}

The mean operative time was 18 minutes ranging from 15 minutes to 23 minutes, from tourniquet inflation to completed dressing. Table 2

\section{Operation time}

\section{Table 2}

Two patients had delayed healing and one patients had delayed epidermal healing which healed by secondary intention. Table 3

No injury to any of the structures had occurred and no patient came back for revision, and all patients had symptoms relieved.

Incidence of complications in study participants $(\mathcal{N}=20)$

\begin{tabular}{|c|c|c|}
\hline Variable & Mean \pm SD & Median (Range) \\
\hline Operation time & $18.0 \pm 2.1$ & $17.5(15-23)$ \\
\hline
\end{tabular}

Table 3

o assess the 6 item score we evaluated the pain severity pre and 3 months postoperative. We found that the mean of the pain severity at night was 3.35 pre-operative and it decreased to 1.6 post-operative. While the mean of the pain severity at day time was 2.7 and it decreased to 1.25 three months post-operative. Table 4 diagram 1

We also found that the mean score of tingling and numbness severity at night was 3.15 preoperative and it decreased to 1.65 three months post- operative. 
While the mean score of tingling and numbness severity at day time was 2.5 preoperative and it decreased to 1.15 three months post-operative. Table 5 diagram 2

Moreover, we found that mean score of awakening at night due to pain severity was 3.10 preoperative and it decreased to 1.35 three months post-operative. While the mean score of awakening at night due to tingling or numbness severity was 3.2 pre-operative and it decreased to 1.6 three months post-operative.Table 6 diagram 3

Regarding all of the above, the mean of the 6 item score of all cases was 17.9 preoperative and it decreased to 8.45 three months post-operative. Table 7 diagram 4

Pain in hands of all study participants $(\mathcal{N}=20)$

\begin{tabular}{|l|c|c||}
\hline \multicolumn{1}{|c|}{ Time } & Pain at night & $\begin{array}{c}\text { Pain during } \\
\text { day time }\end{array}$ \\
\cline { 2 - 4 } & \multicolumn{2}{|c|}{$\begin{array}{c}\text { Mean } \pm \text { SD } \\
\text { Median (Range) }\end{array}$} \\
\cline { 2 - 4 } Pre-operative & $3.35 \pm 0.75$ & $2.70 \pm 0.66$ \\
& $3(2-5)$ & $3(2-4)$ \\
\cline { 2 - 3 } Post-operative & $1.60 \pm 0.61$ & $1.25 \pm 0.44$ \\
& $2(1-3)$ & $1(1-2)$ \\
\hline \hline P-value pre/post & $<\mathbf{0 . 0 0 0 1}^{*}$ & $<\mathbf{0 . 0 0 0 1 *}$ \\
\hline
\end{tabular}

\section{* Significant}

Table 4

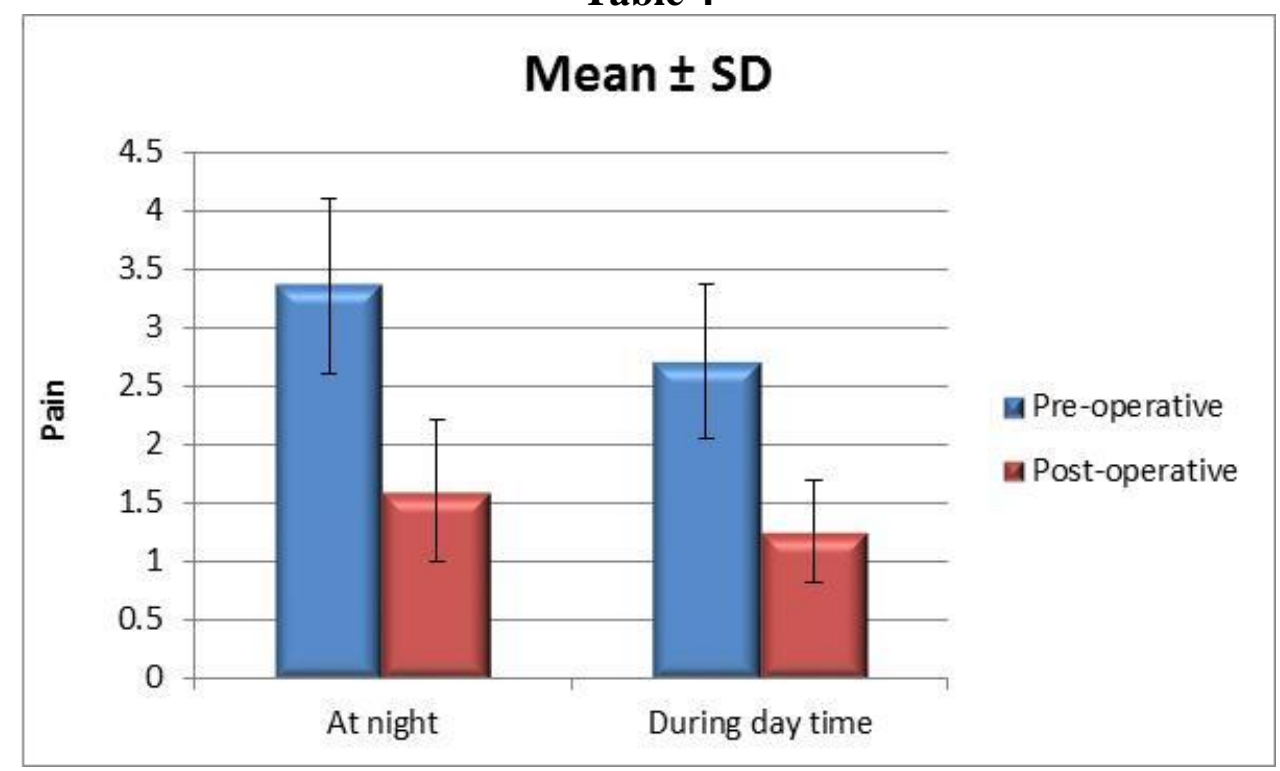

Diagram 1

$\mathcal{N u m b n e s s}$ and tingling in hands of all study participants $(\mathcal{N}=20)$ 


\begin{tabular}{|c|c|c|}
\hline \multirow[t]{2}{*}{ Time } & $\begin{array}{l}\text { Numbness and } \\
\text { tingling at night }\end{array}$ & $\begin{array}{c}\text { Numbness and } \\
\text { tingling during day } \\
\text { time }\end{array}$ \\
\hline & \multicolumn{2}{|c|}{$\begin{array}{c}\text { Mean } \pm \text { SD } \\
\text { Median (Range) }\end{array}$} \\
\hline Pre-operative & $\begin{array}{l}3.15 \pm 0.67 \\
3(2-5)\end{array}$ & $\begin{array}{c}2.50 \pm 0.69 \\
2(2-4)\end{array}$ \\
\hline Post-operative & $\begin{array}{l}1.65 \pm 0.59 \\
2(1-3)\end{array}$ & $\begin{array}{c}1.15 \pm 0.37 \\
1(1-2)\end{array}$ \\
\hline P-value pre/post & $<0.0001^{*}$ & $<0.0001 *$ \\
\hline
\end{tabular}

\section{* Significant}

\section{Table 5}

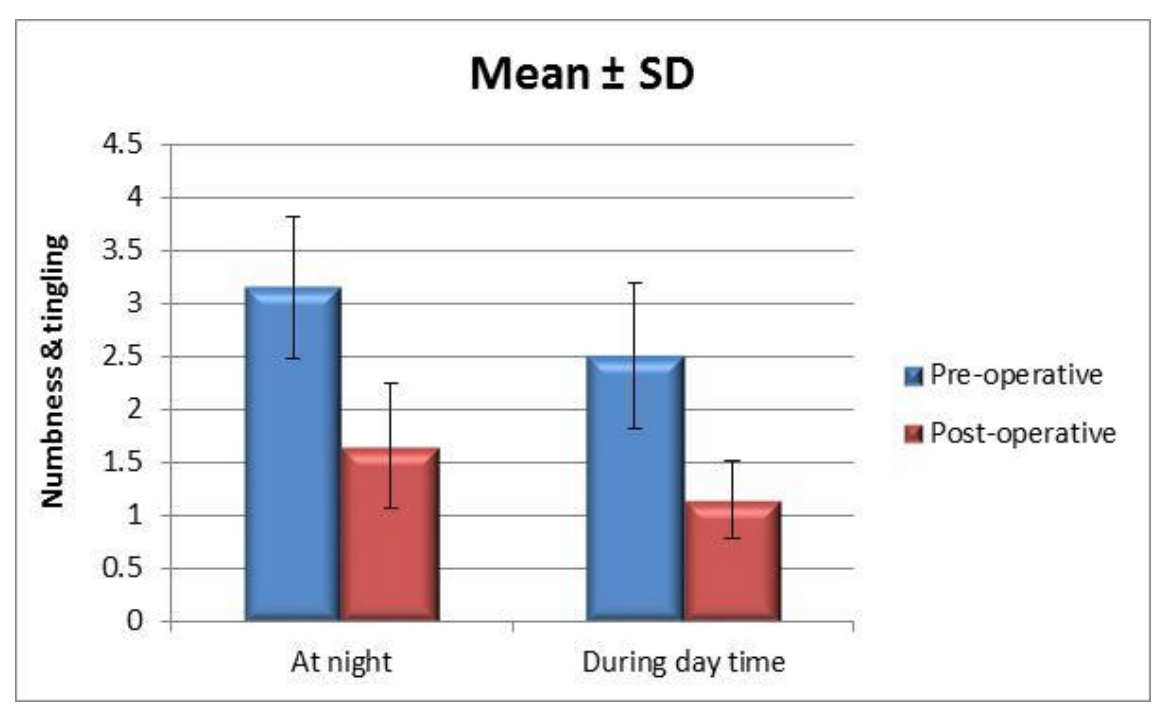

Diagram 2

Symptams that awakening patient up at night $(\mathcal{N}=20)$

\begin{tabular}{|c|c|c||}
\hline \multicolumn{1}{|c|}{ Time } & Pain & $\begin{array}{c}\text { Numbness and } \\
\text { tingling }\end{array}$ \\
\cline { 2 - 3 } & \multicolumn{2}{|c|}{$\begin{array}{c}\text { Mean } \pm \text { SD } \\
\text { Median (Range) }\end{array}$} \\
\hline \multirow{2}{*}{ Pre-operative } & $3.10 \pm 0.97$ & $3.20 \pm 0.95$ \\
& $3(2-5)$ & $3(1-5)$ \\
\hline Post-operative & $1.35 \pm 0.59$ & $1.60 \pm 0.50$ \\
& $1(1-3)$ & $2(1-2)$ \\
\hline P-value $_{\text {pre/post }}$ & $<\mathbf{0 . 0 0 0 1 *}$ & $<\mathbf{0 . 0 0 0 1 *}$ \\
\hline
\end{tabular}

\section{* Significant}

Table 6 


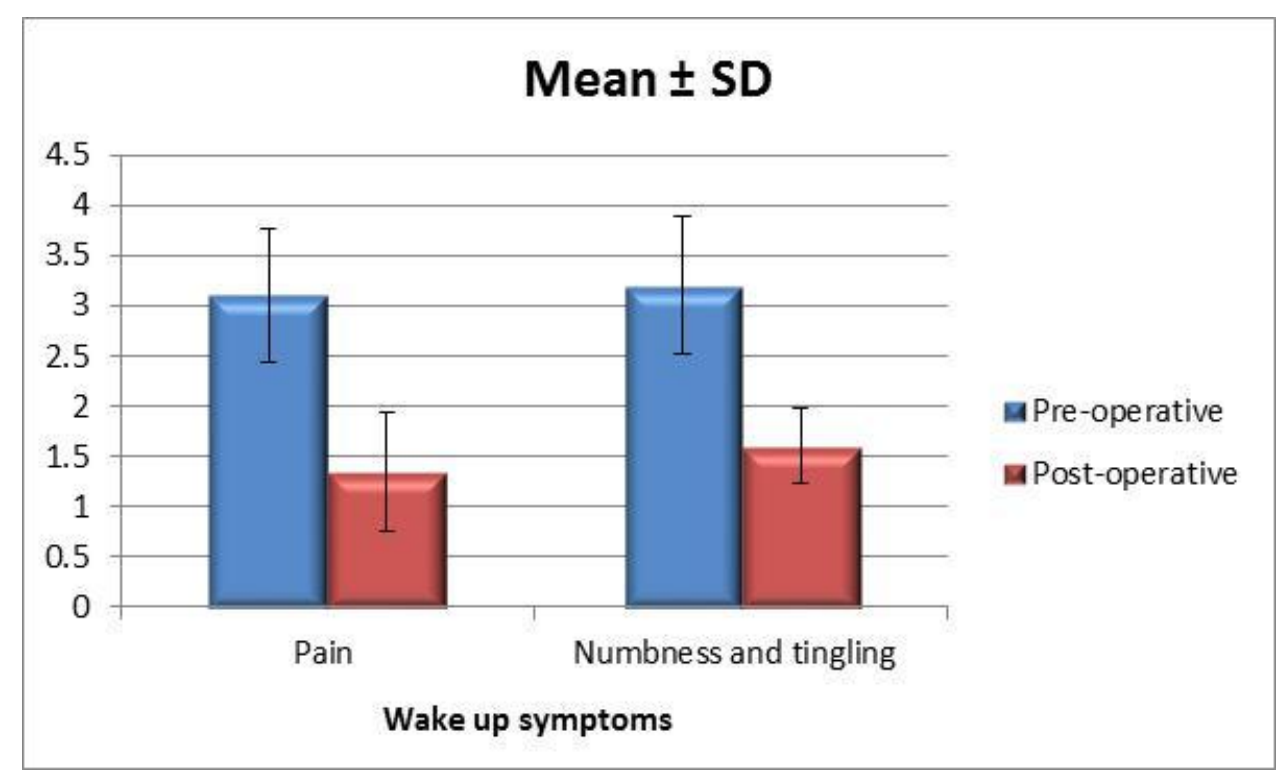

Diagram 3

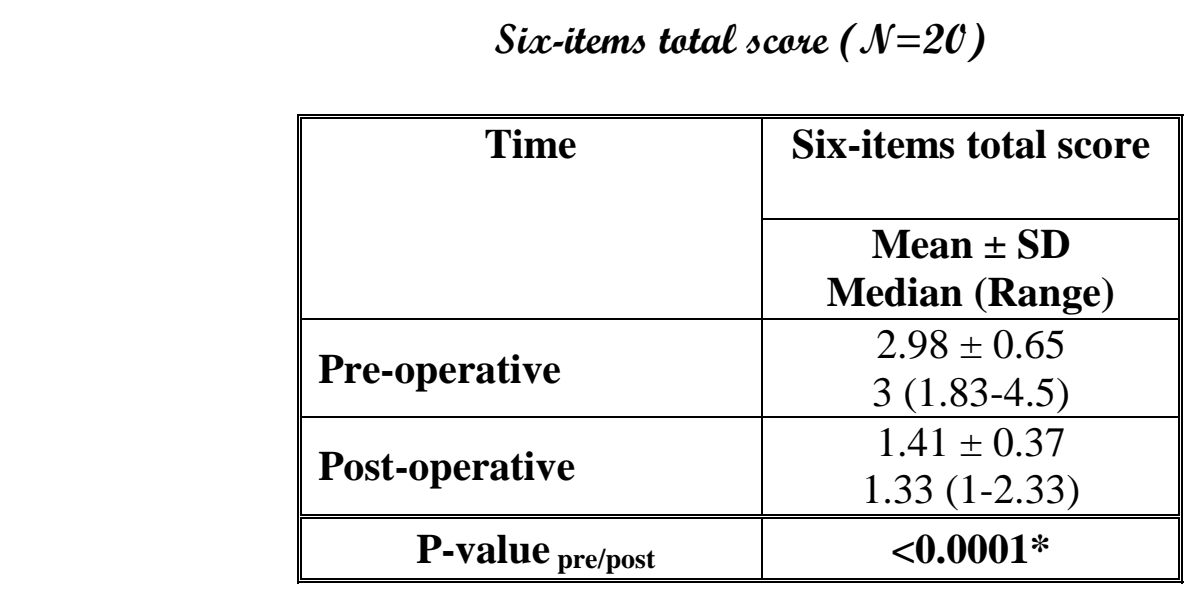

* Significant

Table 7

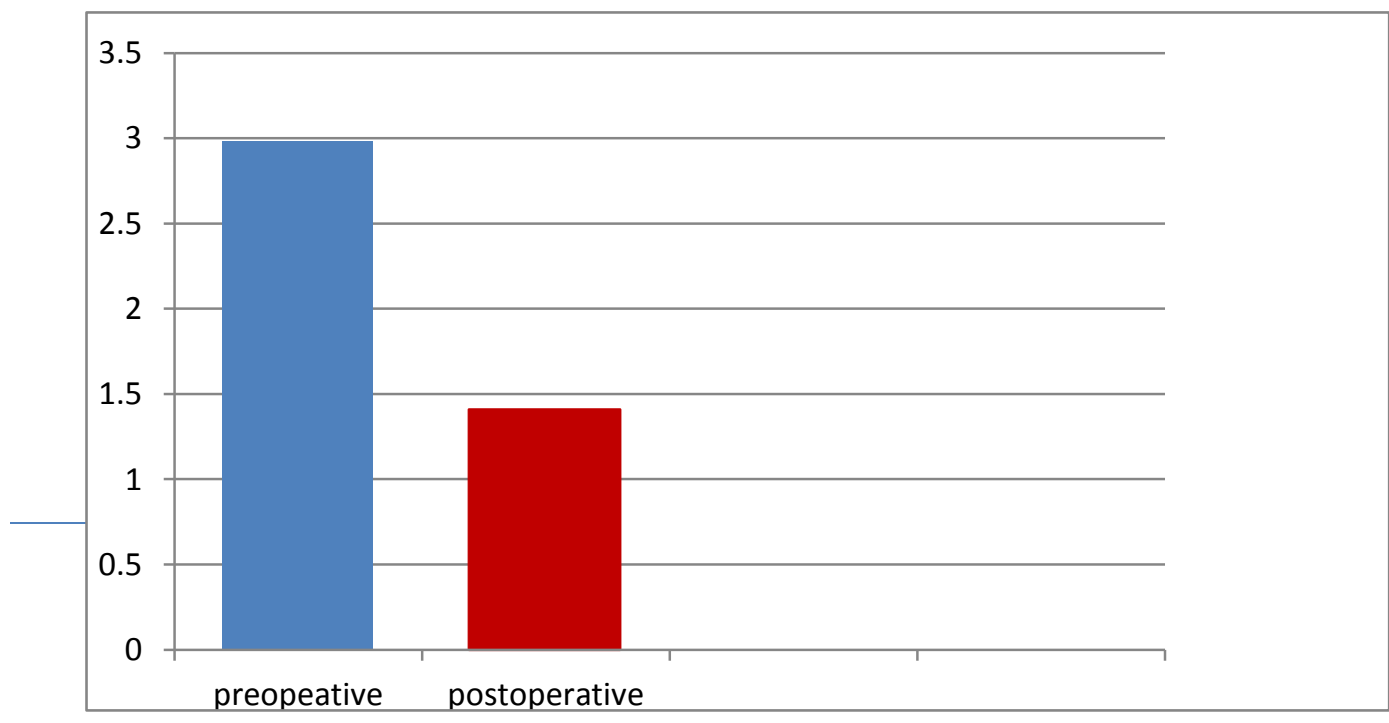




\section{Diagram 4}

According to phalen test, it was positive in 19 cases from 20 cases preoperative, but it was positive only in 2 cases post-operative. Table 8 diagram 5 Tinnel's test was positive at 15 cases pre-operative and 2 cases only post-operative. Table 9 diagram 6

Thalen's test in all study participants $(\mathcal{N}=20)$

\section{* Significant}

Table 8

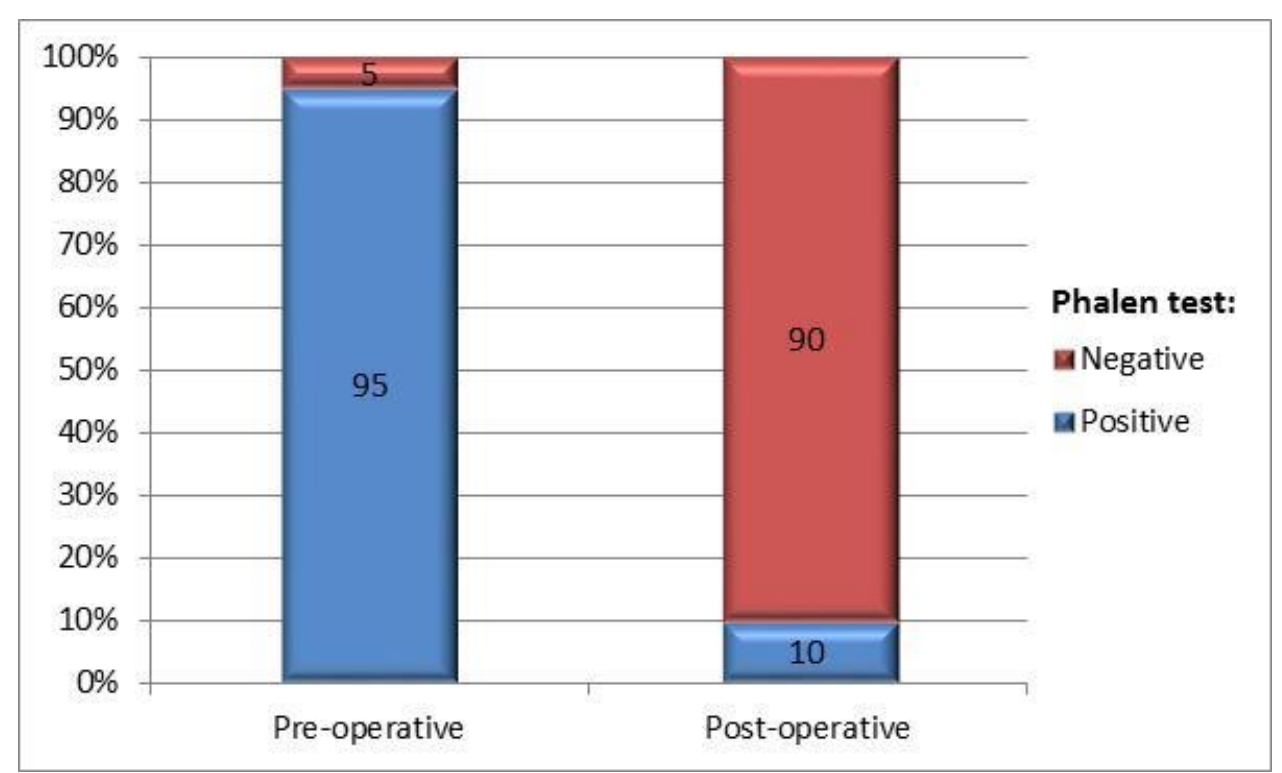

\begin{tabular}{||l|c|c||}
\hline \multirow{2}{*}{ Grades: } & Positive & Negative \\
\cline { 2 - 4 } & \multicolumn{2}{|c||}{ N (\%) } \\
\hline Pre-operative & $19(95.0)$ & Page $47 \frac{1(5.0)}{18(90.0)}$ \\
\hline Post-operative & $2(10.0)$ & 18 \\
\hline \multirow{2}{*}{ P-value } & \multicolumn{2}{|c|}{$<0.0001 *$} \\
\hline
\end{tabular}




\section{Diagram 5}

Tinnel's test in all study participants $(\mathcal{N}=20)$

\section{* Significant}

Table 9

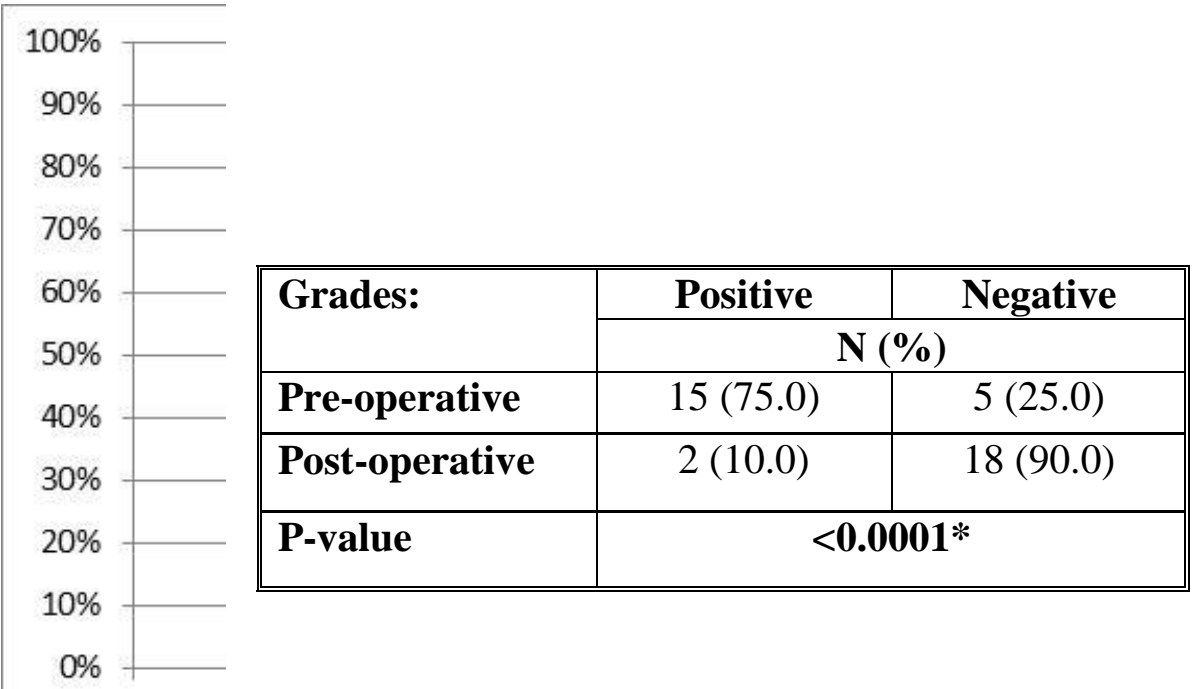

Diagram 6

The mean of motor velocity in 20 cases was 38.34 preoperative, it increased to 55.3 post-operative. The mean of motor latency was 5.8 preoperative and it decreased to 4.8 post-operative. Table 10 diagram 7

The mean of sensory latency was 6.9 preoperative and it decreased to 4.9 postoperative. Table 11 diagram 8 


\begin{tabular}{|c|c|c|}
\hline \\
\hline \multirow{2}{*}{ Time } & & \\
\hline & \multicolumn{2}{|c|}{$\begin{array}{c}\text { Mean } \pm \text { SD } \\
\text { Median (Range) }\end{array}$} \\
\hline Pre-operative & $\begin{array}{c}5.81 \pm 3.36 \\
4.96(3.2-17.5)\end{array}$ & $\begin{array}{c}38.34 \pm 9.95 \\
34.1(28.3-63.8)\end{array}$ \\
\hline Post-operative & $\begin{array}{c}4.84 \pm 2.73 \\
4.11(2.86-15.10) \\
\end{array}$ & $\begin{array}{c}55.33 \pm 11.34 \\
56.85(38.4-71.2) \\
\end{array}$ \\
\hline P-value pre/post & $<0.0001 *$ & $0.002 *$ \\
\hline
\end{tabular}

* Significant

Table 10

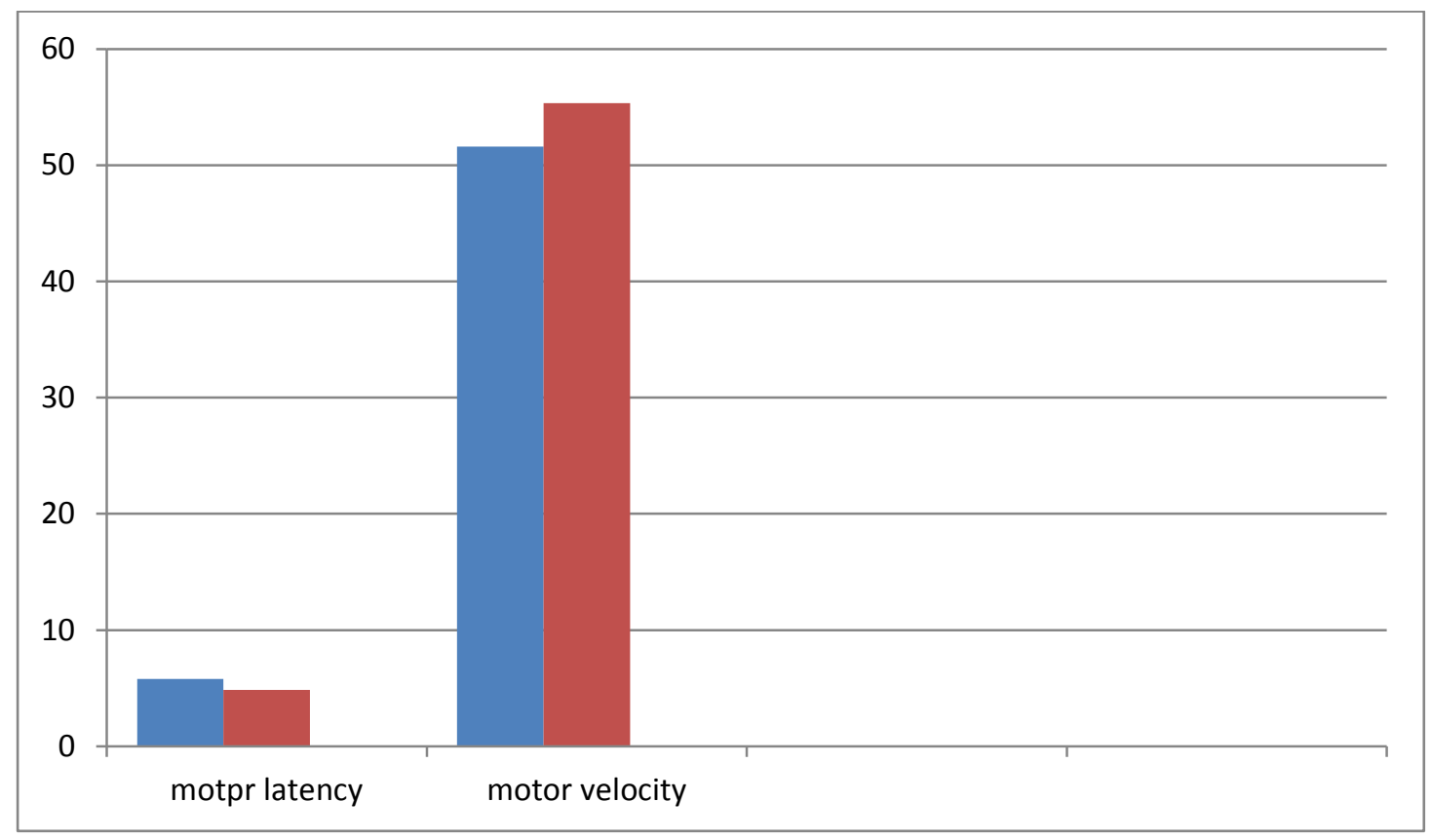

Diagram 7

Sensary latency $(\mathcal{N}=20)$

\begin{tabular}{|l|l|}
\hline Time & Sensory latency \\
\hline
\end{tabular}




\begin{tabular}{||c|c||}
\hline & $\begin{array}{c}\text { Mean } \pm \text { SD } \\
\text { Median (Range) }\end{array}$ \\
\hline Pre-operative & $6.97 \pm 3.49$ \\
& $5.67(3.9-17.8)$ \\
\hline Post-operative & $4.94 \pm 2.62$ \\
\hline P-value $_{\text {pre/post }}$ & $4.02(3.34-14.64)$ \\
\hline \hline
\end{tabular}

* Significant

Table 11

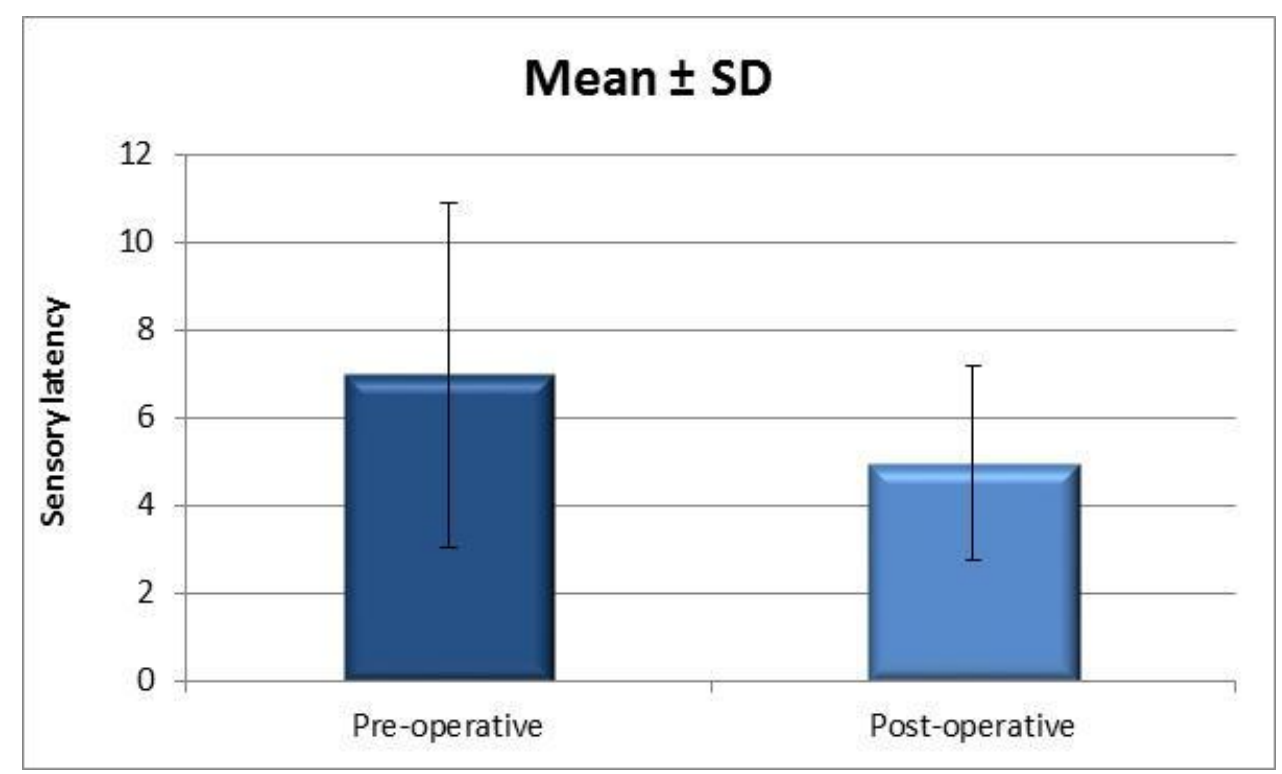

Diagram 8 


\section{DISCUSSION}

Surgical treatment for carpal tunnel syndrome is generally recommended in cases that fail to respond to conservative measures. A variety of surgical techniques have been described for the treatment of carpal tunnel syndrome. ${ }^{[14]}$

The open incision technique has some disadvantages related to the procedure including an unsightly and tender scar, pillar pain, a long healing period and flexor tendon bowstringing ${ }^{[15]}$

Using nasal instruments ensures complete release of carpal ligament and protects the median nerve by means of the blades of nasal turbinate speculum when inserted into the plane above and below the proximal limb of the transverse carpal ligament (TCL) and distal volar forearm fascia (DVFF).

Direct topside visualization of the DVFF and its confluence with the TCL is achieved and reduce the reoperation rate.

In this study we are trying to evaluate the mini incision technique for carpal tunnel decompression using nasal instruments by comparing between the pre-operative and postoperative finding in 20 patient by using 6 item score, Phalen's sign, Tinel's sign and nerve conduction studies, operative time and complications.

In this study, patients were between 26 to55 years with mean $(41.4 \pm 7.7)$. Moreover, 15 of them were females with a percent of $75 \%$ and the other 5 cases were males.

All patients in this study had no other chronic diseases except 4 cases, two cases have a hypertension and two cases have diabetes mellitus.

Regarding to incision length two patients with very thick transverse carpal ligaments we needed to extend the wound to $2.5 \mathrm{~cm}$. , compared to an incision of about $4 \mathrm{~cm}$. in OCTR and two incisions of $1 \mathrm{~cm}$. each for ECTR. ${ }^{[16]}$

Regarding to operative time the mean operative time was 18 minutes from tourniquet inflation to completed dressing, compared to the mean operative time was 19.46 minutes in ECTR and 25.68 in OCTR group ${ }^{[17]}$

Regarding to CTS- 6 score to assess the 6 item score in our study we evaluate the pain severity pre and post-operative. We found that the mean of the pain severity at night was 3.35 pre-operative and it decreased to 1.6 postoperative. While the mean of the pain severity at day time was 2.7 and it decreased to 1.25 postoperatively.

We also found that the mean score of tingling and numbness severity at night was 3.15 preoperative and it decreased to 1.65 postoperative. While the mean score of tingling and numbness severity at day time was 2.5 preoperative and it decreased to 1.15 postoperatively.

Moreover, we found that mean score of awakening at night due to pain severity was 3.10 preoperative and it decreased to 1.35 postoperatively. While the mean score of awakening at night due to tingling or numbness severity was 3.2 pre-operative and it decreased to 1.6 postoperatively.

Regarding all of the above, the mean of the 6 item score of all cases was 2.98 preoperative and it decreased to 1.41 post-operatively.

In a study done by Atroshi who compared preoperative and postoperative CTS-6 scores in 308 patients underwent conventional open CTR, the mean CTS-6 score for the whole sample improved with a mean change of 1.5 ( $\mathrm{p}$.001), the preoperative mean CTS-6 was 3.16 (SD, 0.3.16), the mean CTS-6 score in patients with time since surgery of 71 to 90 days was 1.58 (SD, $0.75), 91$ to 180 days was 1.70 (SD, 0.83), and 
181 to 388 days was 1.59 (SD, 0.79). Adjusting for baseline CTS-6 scores, in that study autors found no significant relationship between change in CTS-6 score and gender, age, or time since surgery. ${ }^{[18]}$

Regarding to Phalen's and Tinnel's tests, in our study and regarding to phalen test, it was positive in 19 cases from 20 cases pre-operative, but it was positive only in 2 cases post-operative. Tinnel's test was positive at 15 cases preoperative and 2 cases only post-operative.

In a study done by Carbone 112 hands of 98 patients operated upon with a mid-palmar mimi-incision technique, declared that Phalen's sign disappeared after 1 month postoperatively for all patients.

Meanwhile Painful percussion remained always present at least in one patient. However, there was a reduction of this sign when compared to baseline evaluation. At the last reassessment, two patients $(5.5 \%)$ presented with a positive test, and $94.5 \%$ were negative. [19]

Regarding to nerve conduction studies, in our study the mean of motor velocity in 20 cases was 38.34 preoperative, it increased to 55.3 postoperatively. The mean of motor latency was 5.8 preoperative and it decreased to 4.8 postoperatively. The mean of sensory latency was 6.9 preoperative and it decreased to 4.9 postoperative.

In a study done by Saxena patients after surgical release with conventional open CTR showed significant improvement in nerve sensory velocity (NSV) and nerve motor latency (NML). Nerve motor velocity (NMV) and NSV were significantly improved as early as 1 month post operatively and the nerve sensory latency (NSL) and nerve motor latency (NML) improve much at 3 month, 6 month respectively.

The preoperative mean NSL was 5.23(SD 0.88 ) improved to be 4.46 (SD 0.59), 3.83 (SD $0.54), 3.19$ (SD 0.45) at 1, 3, 6 months respectively postoperatively.
The preoperative mean NSV was 30.12 (SD 3.09) improved to be 39.55 (SD 1.93), 42.36 (SD 2.32), 45.46 (SD 2.76) at 1, 3, 6 months respectively postoperatively.

The preoperative mean NML was 5.23(SD 0.63 ) improved to be 4.72 (SD 0.47), 4.50 (SD 0.37 ), 4.25 (SD 0.35) at 1, 3, 6 months respectively postoperatively.

The preoperative mean NMV was 30.28 (SD 4.30) improved to be 36.55 (SD 5.32), 41.83 (SD 3.88), 44.71 (SD 3.55) at 1, 3, 6 months respectively postoperatively. ${ }^{[20]}$

Regarding to complications, in our study, two patients had delayed healing and one patient had delayed epidermal healing which healed by secondary intention.

No injury to any of the structures had occurred and no patient came back for revision, and all patients had symptoms relieved

Another study has been done by Muppavarapu and his colleague in 2015 on 101 hands to evaluate open carpal tunnel release with use of a nasal turbinate speculum, they found that Carpal tunnel symptoms were relieved in all patients with a high degree of satisfaction. None of the patients had to return to the OR due to incomplete release. . There were no major complications such as infection, neural or vascular damage or severe residual pain. Four patients reported minor residual numbness in their fingers at latest follow up visit, but still with major improvement from their baseline before surgery ${ }^{[21]}$

\section{CONCLUSION}

In cases of a carpel tunnel syndrome, modified open technique by a mini incision technique by using nasal instruments having satisfying results, greatly improves all symptoms like pain severity tingling and numbness severity at day time and at night. No major complications like recurrence or injuries occurred. 


\section{REFERENCES}

1) Bland, J.D., 2005. The relationship of obesity, age, and carpal tunnel syndrome: more complex than was thought? Muscle \& Nerve: Official Journal of the American Association of Electrodiagnostic Medicine, 32(4), pp.527-532.

2) Van, M., Jose, R. M., \& Power, D. 2019.Failed carpal tunnel surgery: A guide to management. Journal of Musculoskeletal Surgery and Research, 3(1), 30.

3) Chammas, M., Boretto, J., Burmann, L.M., Ramos, R.M., dos Santos Neto, F.C. and Silva, J.B., 2014. Síndrome do túnel do carpo-Parte I (anatomia, fisiologia, etiologia e diagnóstico). Revista Brasileira de Ortopedia, 49(5), pp.429-436.

4) Palumbo CF, Szabo RM. 2002. Examination of patients for carpal tunnel syndrome sensibility, provocative, and motor testing.Hand Clin. 18(2):269-77.

5) O'Connor, D., Marshall, S. and Massy-Westropp， N., 2003. Non-surgical treatment (other than steroid injection) for carpal tunnel syndrome. The Cochrane database of systematic reviews, (1), pp.CD003219CD003219.

6) Piazzini, D.B., Aprile, I., Ferrara, P.E., Bertolini, C.A.R.L.O., Tonali, P., Maggi, L.O.R.E.D.A.N.A., Rabini, A.L.E.S.S.I.A., Piantelli, S.E.R.G.I.O. and Padua, L., 2007. A systematic review of conservative treatment of carpal tunnel syndrome. Clinical Rehabilitation, 21(4), pp.299-314.

7) Georgi, P. G., Vesselin, K., \& Martin, A,. 2018. Orthopaedic Surgery for Carpal Tunnel Syndrome. Clin Surg. 2018; 3,2245 .
8) Roure, P. and Masquelet, A.C., 2001. Etude anatomique du coussin graisseux susretinaculaire: application a l'abord chirurgical du canal carpien. Chirurgie de la main, 20(4), pp.287-293.

9) Siegmeth, A.W. and HopkinsonWoolley, J.A., 2006. Standard open decompression in carpal tunnel syndrome compared with a modified open technique preserving the superficial skin nerves: a prospective randomized study. The Journal of hand surgery, 31(9), pp.1483-1489.

10) Klein, R.D., Kotsis, S.V. and Chung, K.C., 2003. Open carpal tunnel release using a 1centimeter incision: technique and outcomes for 104 patients. Plastic and reconstructive surgery, 111(5), pp.1616-1622.

11) Durandeau A. 2008. Syndrome du canal carpien. In: Conférencesd'enseigenemnt de la société franc, aise de chirurgie orthopédique et traumatologique 2008. p.145-60.

12) Chaise, F., Bellemere, P., Friol, J.P., Gaisne, E., Poirier, P. and Menadi, A., 2001. Interruption professionnelle et chirurgie des syndromes du canal carpien. Resultats d'une serie prospective de 233 patients. Chirurgie de la main, 20(2), pp.117-121.

13) Beckenbaugh RD. 2010. Carpal tunnel syndrome. In: Cooney WP,editor. The wrist. Philadelphia: Lippincott Williams \& Wilkins;. p. 1105-36.

14) Einhorn, N., and Leddy, J. P. 1996. Pitfalls of endoscopic carpal tunnel release.The Orthopedic Clinics of North America, 27(2), 373.

15) Nazal, K.T.D., 2010.The mini incision technique for carpal tunnel decompression using nasal instruments.Turkish neurosurgery, 20(3), pp.353-357. 
16) Atroshi, I., Gummesson, C., Johnsson, R. and Ornstein, E., 2003.Diagnostic properties of nerve conduction tests in population-based carpal tunnel syndrome. BMC musculoskeletal disorders, 4(1), p.9.

17) Ismail, M, S, A., Alexander and Ibrahim, M, A., 2018. Outcome of endoscopic carpal tunnel release versus open carpal tunnel release in diabetic patients.

18) Atroshi, I., Lyrén, P.E., Ornstein, E. and Gummesson, C., 2011. The six-item CTS symptoms scale and palmar pain scale in carpal tunnel syndrome.The Journal of hand surgery, 36(5), pp.788-794.

19) CARBONE, S.E., PAULA, L.L., SANTOS, L.M.M., GOMES, J.B., SANTOS, F.F., Albertoni, W.M. and Fernandes, C.H., 2006. Avaliação clínica a longo prazo-pelo sinal de Phalen, Tinel e parestesia noturna-dos pacientes submetidos a cirurgia de liberação do túnel do carpo com instrumento de Paine ${ }^{\circledR}$. Acta Ortop Bras, 14(4), p.213.

20) Saxena, V., Rajak, M.K., Thakur, R. and Kumar, S., 2017. Electrophysiological and functional outcome after carpal tunnel release in patients with carpal tunnel syndrome: A prospective evaluation. International Journal of Orthopaedics, 3(4), pp.675-678.

21) Muppavarapu, R. C., Rajaee, S. S., Ruchelsman, D. E., \& Belsky, M. R. (2015). Open Carpal Tunnel Release With Use of a Nasal Turbinate Speculum. American Journal of Orthopedics. 